\title{
Consumer perception and behaviour related to low-alcohol wine: do people overcompensate?
}

\author{
Tamara Bucher $^{1,2, *}$, Eveline Frey ${ }^{1,2}$, Magdalena Wilczynska ${ }^{2,3}$, Kristine Deroover $^{2,4}$ (1) \\ and Simone Dohle 5 \\ 'School of Environmental and Life Science, Faculty of Science, The University of Newcastle, Callaghan, NSW 2308, \\ Australia: ${ }^{2}$ Priority Research Centre for Physical Activity and Nutrition, The University of Newcastle, Callaghan, NSW \\ 2308, Australia: ${ }^{3}$ School of Psychology, Faculty of Science, The University of Newcastle, Callaghan, NSW 2308, \\ Australia: ${ }^{4}$ School of Health Sciences, Faculty of Health and Medicine, The University of Newcastle, Callaghan, \\ NSW 2308, Australia: ${ }^{5}$ Social Cognition Center Cologne, University of Cologne, 50931 Köln, Germany
}

Submitted 23 July 2019: Final revision received 13 November 2019: Accepted 19 December 2019: First published online 19 May 2020

\begin{abstract}
Objective: Compared with standard wines, low-alcohol wines may have several social and health benefits. Innovative production processes have led to highquality light wines. It is, however, unclear how consumers perceive and consume these alcohol-reduced wines. The current study aimed to investigate how people evaluate low-alcohol wine (Sauvignon Blanc) and if the reduction in alcohol and the information that a wine is low in alcohol influences consumption.

Design: Randomised controlled trial (RCT).

Setting: Participants were invited to a wine tasting and randomised into one of the three conditions: they either tasted a 'new white wine' (12.5\% alcohol content), a 'new low-alcohol white wine' ( $8.0 \%$ alcohol content) or they tasted the lowalcohol wine but were not aware that the wine was reduced in alcohol (lowalcohol, blinded).

Participants: Ninety participants ( $42 \%$ male, mean age $=41$ (SD 14) years).

Results: Mean comparisons showed similar ratings for the low-alcohol conditions and the standard alcohol condition (mean $>5 \cdot 6 / 7$ ). The mean consumed amount across all conditions did not differ $\left(162(\mathrm{SD} 71) \mathrm{ml},\left(F_{2,86}=0.43, P>0.05\right)\right)$, hence people who tasted the low-alcohol wine consumed approximately $30 \%$ less alcohol. However, participants were willing to pay more for the normal wine compared with the low-alcohol wine, $\left(F_{2,87}=3 \cdot 14, P<0 \cdot 05\right)$.

Conclusions: Participants did not alter their drinking behaviour in response to the reduced alcohol content, and the low-alcohol wine was perceived positively. There might be an emerging market potential for wine of reduced alcohol content, but consumers may not be willing to pay the same price as for the standard wine.
\end{abstract}

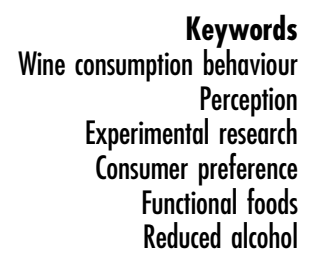

Alcohol consumption is associated with a variety of negative social and health-related outcomes, including an increased risk for cancer ${ }^{(1)}$. A recent review found that alcohol was the seventh leading risk for premature death in 2016 and concluded that no amount of alcohol is safe ${ }^{(2)}$. Due to these reasons, the WHO conducts a global strategy to reduce the harmful use of alcohol ${ }^{(1)}$. One proposed strategy to achieve this goal is to reduce the alcoholic strength of beverages.

Literature has shown that health is of increasing interest to consumers, and their food and wine decision-making ${ }^{(3-6)}$. Low-alcoholic beverages are often perceived as a way to reduce the negative health-related consequences caused by alcohol consumption and therefore suit the general trend towards living healthier lifestyles ${ }^{(7,8)}$. One survey conducted in Australia showed a consumer interest of $6-8 \%(9)$, whereas another Australian survey reported that the relative acceptance of low-alcohol wine was $16 \%$, but $40 \%$ of the participants would consider the purchase of low-alcohol wine if it would taste the same as standard wine ${ }^{(7)}$.

Innovations in the production process of low-alcohol wine have resulted in low-alcohol wine with highly acceptable sensory properties and a taste very similar to the standard wine. Only a limited amount of literature looked into the way consumers perceive and rate low-alcohol wine $^{(8,10,11)}$. Research has shown that, through mere 
exposure, the alcohol-related attributes in the sensory profile of a wine can be perceived as that what makes wine taste like wine, resulting in depreciation of wines with reduced alcohol content because of the lack of the alcohol taste ${ }^{(12,13)}$. Some experimental studies found that the expected quality for 'low-alcohol'-labelled wine was significantly lower as compared with a standard wine ${ }^{(14)}$. However, in the same study, taste ratings of low-alcohol wines ( $9 \%$ alcohol) did not differ from ratings of standard wines (13\% alcohol), neither under blind condition nor if participants were aware they were consuming low-alcohol wine ${ }^{(14)}$. In the present study, it was hypothesised that the low-alcohol label will result in a lower perceived quality and therefore a lower rating of the wine. Furthermore, it was hypothesised that participants in both low-alcohol conditions will rate the wine lower than those in the standard condition because they are not familiar with the taste.

Previous studies on consumer's willingness to pay for non-standard wines with health benefits resulted in mixed results. Some found that perceived healthfulness was not one of the main purchase criteria ${ }^{(15)}$ and health-related labels, such as 'no sulphites added' or 'organic', only played a small role compared with price and taste ${ }^{(16)}$. Others found that consumers were willing to pay more for wine made with grapes enriched in resveratrol, a phenolic that has been suggested to have antioxidant, cardioprotective and cancer chemopreventive effects ${ }^{(17,18)}$. In the present study, it was hypothesised that participants would be willing to pay less for the low-alcohol wine than for standard wine, as it is assumed that participants would not be familiar with the product and its (health) benefits, and a perceived lower quality would result in lower willingness to pay.

A main benefit of low-alcohol wine may be that, when replacing standard alcoholic beverages and without increasing the volume of alcoholic beverages consumed, the total intake of alcohol, and the likeliness of its harmful effects, will be reduced. In addition, low-alcohol beverages may also bring social benefits, including less aggressive and more acceptable social behaviour in general. However, overconsumption, that is, an increased intake of lower strength products resulting in an overall increase in alcohol intake, has been discussed in past research as a counter argument against the promotion of lower alcohol beverages $^{(19)}$. In a study by Higgs et al. ${ }^{(20)}$, in which participants were instructed to consume a target drink 'at a rate that is comfortable' for them, participants consumed a beverage with a higher percentage of alcohol at a slower rate. This would indicate that people would consume less of a stronger alcoholic beverage within a fixed time frame. Previous studies in the area of food research showed that labels on food products, such as 'light' or 'low-fat', could trigger an increase in consumption ${ }^{(21,22)}$. A higher consumption of products with health-indicating labels occurred, compared with standard products with no health-indicating label. According to this finding, it is possible that such behaviour could also be observed with low-alcohol-labelled products, as they also suggest positive health effects. It is therefore hypothesised that participants in the low-alcohol condition will consume more wine than those participants who will be offered the standard wine.

In summary, there is some evidence that low-alcohol labelling on wine might influence consumer perception and behaviour; however, more insight from experimental studies is needed. The present study aims to test consumer perception and consumption behaviour related to 'lowalcohol' white wine. The purpose of this study is three-fold: to explore participants' perceptions of low-alcohol wine and the influence of a low-alcohol label on these perceptions, to investigate participants' willingness to pay for low-alcohol wine and finally, to explore the effect of a low-alcohol label on consumption behaviour, and to investigate whether it results in overconsumption.

\section{Methods}

\section{Design}

Participants were randomly assigned to one of the experimental conditions: 1) low-alcohol wine, 2) low-alcohol wine (blinded) or to the control condition 3) standard wine.

Data collection was completed at the University of Newcastle City campus between January and February 2018. The study procedure was approved by the Human Research Ethics Committee of the University of Newcastle (H-2017-0419) . The study manager had a valid 'Responsible Service of Alcohol' certificate, which allows serving alcohol in Australia.

\section{Participants}

Adult participants were recruited through announcements on social media and local media channels, that is, newspaper 'Newcastle Herald', the website 'HUNTER hunter', and on local radio and TV. Interested potential participants then had to contact the study manager to check their eligibility for participation in this study. Following inclusion criteria were taken into account: (i) aged 18 years or older; (ii) not allergic to white wine and (iii) agreed not to drive within $4 \mathrm{~h}$ after the tasting. If all criteria were met, the participants received an email with an information sheet and the consent form. They could then register for a study appointment via an online booking system. Sample size was determined prior to data collection using G*Power $3^{(23)}$. This analysis resulted in a required total sample size of eighty-four participants, which would ensure a power of 0.8 while testing with an alpha-error of 0.05 , supposing the size of the effect is medium to large $(f=0.35)$. However, slightly more participants were recruited in case that some of the participants had to be excluded. Ninety-two men and 
women attended and participated in this experiment. Two participants were excluded from the analysis because of incomplete data collection. All participants provided written informed consent before participation in the study.

\section{Experimental procedure}

The participants were invited to taste a new white wine (Sauvignon Blanc (SB) 2016) and were told that the aim of the study was to evaluate this new wine. Participants did not receive a financial incentive for participation in the current study. They were randomly allocated to one of the three conditions: 'low-alcohol', 'low-alcohol blind' or 'standard' (control). Participants in the low-alcohol condition received low-alcohol wine (8\%) and were invited for a tasting of a 'new low-alcohol white wine'. Participants in the non-blinded experimental condition received an information sheet which included some facts about the grape varieties, region, etc., including the alcoholic strength, that is, $8 \%$. Participants in the low-alcohol blinded condition received the same low-alcohol wine but were invited for a tasting of a 'new white wine' on the market. Hence, they were not aware that they tasted a product that contained less alcohol. Participants in the control condition received a standard wine and were also invited for a tasting of a new white wine on the market. The provided wine was a SB, 2016, that was available in two variations. Variation one was the standard SB wine, with an alcohol content of $12.5 \%$. This wine was offered to the control condition ('standard wine' condition). Variation two was the same wine (SB 2016) but with a reduced content of alcohol ( $8 \%$ ). This wine was offered to participants belonging to the low-alcohol condition and the low-alcohol blind condition.

An individual appointment for each participant was made. For the tasting, the participant was seated at a table. In front of the participant, the following items were placed on the table. On the right, a wine bottle containing $300 \mathrm{ml}$ of SB (either low or standard SB) and a standard bell-shaped wine glass (IKEA SVALKA, $250 \mathrm{ml}$ ) were provided. A sheet of paper was taped around the wine bottle in such a way that the amount of wine contained in the bottle was not discernible, and participants would not be influenced by the amount of wine left in the bottle, to minimise an anchoring effect or social desirability bias. Next to the wine bottle, a jug with one litre of tap water and a cup were placed on the table. On their left, participants could find a white plate with five slices of plain white bread. Before they started with the study, participants were advised to read the instructions. The written instructions informed the participants that they were going to taste a new lowalcohol wine (low-alcohol condition) or a new white wine (low-alcohol blind condition and standard condition). They were also informed that they could taste as much wine as they liked and could help themselves to wine, water, and bread during the tasting. Additionally, participants were instructed to stay in the study room for the full $20 \mathrm{~min}$ that were provided for the tasting. A timer set to $20 \mathrm{~min}$ was visible to all participants. Once participants had read the written instructions, the study manager replaced the sheet with a product sheet of the wine and a tablet with an online survey. The survey was programmed using Qualtrics.

\section{Wine}

The wine that was used in the present study was produced at a local winery in the Hunter Valley (Tamburlaine Wines, NSW, Australia). The low-alcohol variant of the wine was produced for the purpose of this study and is not currently available on the market. The grape of the wine came from Orange (a wine region in NSW, Australia) and was $100 \%$ $\mathrm{SB}$. The standard variant of the SB contains $12.5 \%$ of alcohol. The wine maker used reverse osmosis to produce a low-alcohol wine for the purpose of the current study. Alcohol and water have a lower molecular weight than the other wine components. Consequently, they can be separated from the rest of the wine using a membrane that only allows these low-molecular-weight molecules to pass. The alcohol is then separated from the permeate by column distillation, and the permeate with less ethanol is returned into the wine. This process has the advantage that alcohol is selectively reduced, while flavours, colours and tannins are preserved. This method is often used to balance wines in sunny years when the sugar content of the grapes is higher than usual and the resulting alcohol content is too high $^{(24,25)}$. After the reverse osmosis process, the wine used for the study contained $8 \%$ of alcohol.

\section{Measures}

An online questionnaire assessed the participant's perceptions of the tasted wine through several questions. Six items evaluated the following properties of the wine: dryness, sweetness, smoothness, butteriness, crispness and fruitiness. Answers were given on a seven-point Likert scale from 1 (strongly disagree) to 7 (strongly agree). These items were included in the questionnaire in order to mask the actual purpose of the study. Two questions were used to measure how much participants liked the wine. The first item was: 'Drinking this wine was pleasant'. Answers were given on a seven-point Likert scale from 1 (strongly disagree) to 7 (strongly agree). The second item was: 'Please indicate how much you liked the low-alcohol wine/new white wine Sauvignon Blanc that you have tasted'. Answers were given from 1 (dislike a great deal) to 7 (like a great deal). To assess how much participants were willing to pay for the tasted wine, they were asked to give an answer on a five-point Likert scale from $1=\$ 0 A U D, 2=\$ 0-10 A U D, 3=\$ 10-15 A U D, 4=\$ 15-20 A U D$, $5=\$ 20$ AUD or more.

In addition to that, participants were asked how much wine (red, white) they drink on a weekly basis. Participants were also asked if they were currently trying to reduce their 
alcohol consumption and reported socio-demographic characteristics such as gender and age.

The participants in the blinded experimental condition received one additional question as they were debriefed at the very end of the survey and then asked if they had noticed any differences between the low-alcohol wine they have just tasted and a standard wine. Answers were given on a Likert scale from 1 (definitely yes) to 4 (definitely not).

The amount of consumed wine was measured with a measuring scale. A density of $1 \mathrm{~g} / \mathrm{cm}^{3}$ was assumed (e.g. $100 \mathrm{ml}$ of wine equals $100 \mathrm{~g}$ ). Each participant had been offered $300 \mathrm{ml}$ of chilled wine, and after the trial, the leftover wine in both the bottle and the glass was measured to determine how much wine the participant consumed. Based on the consumed amount of wine, the consumed amount of alcohol was calculated by multiplying the volume by the relevant alcohol percentage. Water and bread consumption were measured as control variables.

\section{Statistical analysis}

Statistical analysis was performed using IBM SPSS Statistics version 24 (SPSS Inc.). Normal distribution of data was tested with the Kolmogorov-Smirnov test, and homogeneity of variance was tested with the Levene's test. Descriptive statistics were used for the socio-demographic measures, average wine consumption measures, and whether participants were trying to reduce alcohol consumption. Differences between the conditions were measured with $\chi^{2}$ for the categorical variables and oneway ANOVA for the continuous variables. Normally distributed data were summarised as means $(M)$ and standard deviation (SD). Significance level was set at $P<0 \cdot 05$. Oneway ANOVA were conducted to compare the mean consumed amount of wine, alcohol, bread and water, the willingness to pay, liking and pleasantness of the wine between the three experimental conditions. Test values $(F)$, degrees of freedom $(\mathrm{df})$ and significance $(P)$ were reported. To determine which conditions differed significantly from each other, post hoc comparisons (Tukey HSD) were reported.

\section{Results}

Ninety participants were included in the analysis. The sample consisted of thirty-eight males and fifty-two females, with a mean age of 41 years $(\mathrm{SD}=14 \cdot 06, \mathrm{Min}=21$, Max $=75$ ). Only $7 \cdot 8 \%$ of the sample was trying to reduce their alcohol consumption to a great extent, and $92.2 \%$ was not trying or trying only a little to reduce their alcohol consumption. Table 1 describes age, gender, the participants' average wine consumption per week and their aim to reduce their alcohol consumption in total and per condition. No significant differences between conditions were found for these variables.
Table 1 Description of study population $(n 90)$

\begin{tabular}{|c|c|c|c|c|}
\hline & $\begin{array}{c}\text { Total } \\
\text { (n 90) }\end{array}$ & $\begin{array}{c}\text { Control } \\
\text { (standard } \\
\text { wine) } \\
(n 27)\end{array}$ & $\begin{array}{l}\text { Low- } \\
\text { alcohol } \\
\text { wine } \\
(n 33)\end{array}$ & $\begin{array}{l}\text { Low- } \\
\text { alcohol } \\
\text { wine } \\
\text { blind } \\
\text { (n 30) }\end{array}$ \\
\hline \multicolumn{5}{|l|}{ Gender } \\
\hline Male & 38 & 11 & 13 & 14 \\
\hline Female & 52 & 16 & 20 & 16 \\
\hline \multicolumn{5}{|l|}{ Age (years) } \\
\hline Mean & $40 \cdot 60$ & 44.48 & $40 \cdot 06$ & $37 \cdot 70$ \\
\hline SD & 14.06 & 14.06 & $13 \cdot 67$ & $14 \cdot 16$ \\
\hline \multicolumn{5}{|c|}{$\begin{array}{l}\text { Red wine consumption } \\
\text { per week }(\mathrm{ml})^{\star}\end{array}$} \\
\hline Mean & 4.43 & 4.56 & $3 \cdot 88$ & 4.93 \\
\hline SD & 2.52 & $2 \cdot 26$ & $2 \cdot 67$ & 2.53 \\
\hline \multicolumn{5}{|l|}{$\begin{array}{l}\text { White wine } \\
\text { consumption } \\
\text { per week }(\mathrm{ml})^{\star}\end{array}$} \\
\hline Mean & $5 \cdot 22$ & $5 \cdot 11$ & $5 \cdot 18$ & 5.37 \\
\hline SD & 2.38 & $2 \cdot 29$ & 2.43 & 2.48 \\
\hline \multicolumn{5}{|l|}{$\begin{array}{l}\text { Trying to reduce } \\
\text { consumption }\end{array}$} \\
\hline Not at all & 28 & 10 & 11 & 7 \\
\hline Very little & 30 & 9 & 11 & 10 \\
\hline Somewhat & 25 & 6 & 9 & 10 \\
\hline To a great extent & 7 & 2 & 2 & 3 \\
\hline
\end{tabular}

${ }^{*}$ Red and white wine consumption were measured on a scale $(1: 0 \mathrm{ml} ; 1:<100 \mathrm{ml}$; 2:100-200 ml; $3: 200-300 \mathrm{ml} ; \quad 4: \quad 300-400 \mathrm{ml} ; \quad 5: 400-500 \mathrm{ml} ; \quad 6: 500-750 \mathrm{ml}$; 7: $750-1500 \mathrm{ml} ; 8:>1500 \mathrm{ml}$ )

Twenty-nine (out of 30) participants of the blinded experimental condition answered the question whether they noticed any differences between the low-alcohol wine and a standard wine. Seven participants said 'definitely yes', five participants answered 'probably yes', nine answered 'probably not' and eight answered 'definitely not'.

Table 2 shows the results for the comparison analyses for perceptions, willingness to pay and consumption behaviour. The mean amount of wine consumed in the three conditions ( $M=161.96, \mathrm{SD}=70.98)$ was not significantly different $\left(F_{2,86}=0.43, P=0.65\right)$. Consequently, the amount of alcohol consumed $(M=14 \cdot 96, \mathrm{SD}=7 \cdot 28)$ differed significantly $\left(F_{2,86}=6 \cdot 62, P=0.002, \eta^{2}=0 \cdot 13\right)$, and the participants in the low-alcohol conditions drank approximately $30 \%$ less alcohol than those in the control condition. Figure 1 shows the mean wine and alcohol consumption for each group.

Neither the amount of bread (slices) consumed ( $\left.M=2 \cdot 04, \mathrm{SD}=1 \cdot 35, P=0.86, F_{2,87}=0 \cdot 15\right)$ nor the amount of water $(\mathrm{ml})$ consumed $(M=143 \cdot 22, \mathrm{SD}=115 \cdot 6, P=0 \cdot 22$, $\left.F_{2,85}=1.56\right)$ differed significantly between groups. However, the willingness to pay was significantly different between groups $\left(F_{2,87}=3 \cdot 14, P=0 \cdot 048, \eta^{2}=0 \cdot 07\right)$. A post boc Tukey test showed that the low-alcohol $(M=3 \cdot 09$, $\mathrm{SD}=0.91)$ and the control condition (standard wine) $(M=3.63, \mathrm{SD}=0.79)$ differed significantly at $P<0.05$; the low-alcohol blind condition $(M=3 \cdot 27, \mathrm{SD}=0.79)$ was not significantly different from the other two conditions.

Further, ANOVA showed that there was no significant difference between the groups in liking of the wine 
Table 2 Summary of the results $(n 90)$

\begin{tabular}{|c|c|c|c|c|c|c|c|}
\hline & \multicolumn{2}{|c|}{$\begin{array}{l}\text { Control (standard } \\
\text { wine) } \\
(n 27) \\
\end{array}$} & \multicolumn{2}{|c|}{$\begin{array}{l}\text { Low-alcohol wine } \\
(n \text { 33) }\end{array}$} & \multicolumn{2}{|c|}{$\begin{array}{l}\text { Low-alcohol wine } \\
\text { blind }(n 30)\end{array}$} & \multirow[b]{2}{*}{ Test value ANOVA $(F)$} \\
\hline & $M$ & SD & $M$ & SD & $M$ & SD & \\
\hline Wine consumed $(\mathrm{ml}) \dagger$ & $152 \cdot 42$ & 73.06 & $162 \cdot 00$ & 75.54 & $170 \cdot 17$ & $65 \cdot 13$ & $F_{2,86}=0.43, P=0.65$ \\
\hline Alcohol consumed $(\mathrm{ml}) \dagger$ & $19 \cdot 05^{a}$ & $9 \cdot 13$ & $12.96^{\mathrm{b}}$ & 6.04 & $13 \cdot 61^{\mathrm{b}}$ & $5 \cdot 21$ & $F_{2,86}=6.62^{*}, P<0.01\left(\eta^{2}=0.13\right)$ \\
\hline Bread consumed (slices) & $2 \cdot 11$ & 1.45 & 2.09 & 1.33 & 1.93 & 1.31 & $F_{2,87}=0.15, P=0.86$ \\
\hline Water consumed (ml)‡ & $158 \cdot 26$ & $128 \cdot 97$ & $159 \cdot 25$ & $119 \cdot 32$ & 111.55 & 104.58 & $F_{2,85}=1.56, P=0.22$ \\
\hline Liking of the wine§ & $6 \cdot 22$ & 0.93 & $5 \cdot 61$ & $1 \cdot 32$ & $5 \cdot 87$ & 1.34 & $F_{2,87}=2 \cdot 01, P=0.14$ \\
\hline Pleasantness to drink $\|$ & 6.04 & 0.90 & $5 \cdot 64$ & 1.25 & 6.00 & 0.98 & $F_{2,87}=1.35, P=0.27$ \\
\hline Willingness to pay & $3 \cdot 63^{a}$ & 0.79 & $3 \cdot 09^{b}$ & 0.91 & $3 \cdot 27^{a, b}$ & 0.79 & $F_{2,87}=3.14^{*}, P<0.05\left(\eta^{2}=0.07\right)$ \\
\hline
\end{tabular}

†ln the analysis of the consumed amount of wine, a cut-off score of $\geq 30 \mathrm{ml}$ was used, resulting in the exclusion of one participant for that particular analysis ( $n$ 89). $\ddagger$ The water consumption of two participants was not recorded $(n 88)$.

§Liking the wine was measured on a seven-point scale.

|Pleasantness to drink the wine was measured on a seven-point scale.

TWillingness to pay was measured on a five-point scale ( $1=\$ 0 A U D ; 2=\$ 0-10 A U D ; 3=\$ 10-15 A U D ; 4=\$ 15-20 A U D ; 5=\$ 20 A U D$ or more).

$\mathrm{a}, \mathrm{b}$ Post hoc multiple comparisons were performed using Tukey-HSD test, for three comparisons. Different superscript letters indicate significant differences (mean values $<0.05$ ) between conditions.

${ }^{*} P<0.05$.

$\left(F_{2,87}=2 \cdot 01, P=0 \cdot 14\right)$, nor in perceived pleasantness to drink the wine $\left(F_{2,87}=1 \cdot 35, P=0 \cdot 27\right)$.

\section{Discussion}

\section{Acceptance of low-alcobol wine}

Within the evaluations 'liking of the new wine' and 'pleasantness to drink the wine', there were no significant differences in mean values between participants in the low-alcohol condition and the other two conditions, that is, control condition (standard wine) and low-alcohol blind condition. Both wines (low-alcohol wine and standard wine) received high ratings. These positive perceptions of low-alcohol wine support the assumption that production methods have improved within the last years, resulting in low-alcohol wine with good sensory qualities. It should be noted that the acceptance of low-alcohol wine may differ between countries.

A study by d'Hauteville(26), for example, found that people from the UK $(26.7 \%)$ were more willing to accept the concept of low-alcohol wine compared with people from Germany (19.5\%) or France (12.4\%). One possible explanation for this may be that other low-alcohol beverages, such as low-alcohol beer, have been well established yet in countries like the $\mathrm{UK}^{(27)}$, whereas lower acceptance for low-alcohol wine in France could be due to the long wine tradition within the French culture. Future studies may wish to compare different countries and investigate how cultural aspects influence the acceptance of low-alcohol wine.

\section{Willingness to pay}

A significant difference between the conditions was also found for 'willingness to pay'. Participants were willing to pay more for standard wine than for low-alcohol wine. This finding is in line with the previous research, suggesting that in wine consumer decision-making, price and taste play a bigger role than health benefits ${ }^{(15,16)}$. As price has been described as an indicator of quality ${ }^{(27)}$, a lower willingness to pay for low-alcohol wine may indicate that it is perceived to be a lower quality product. Also, consumers may assume that pricing should be based on alcoholic strength. Spirits, for example, have a higher alcoholic content and are often more expensive, whereas beer has a lower alcoholic content and is generally cheaper. This may cause the consumer to expect that a wine with a lower alcoholic strength will be cheaper than a standard wine. Furthermore, consumers may not be aware that alcohol reduction involves additional processing steps ${ }^{(28)}$, which add to the costs. It may be beneficial to inform consumers about the process and the technology used to reduce alcohol. Past research showed that consumers who trust the technological developments in agribusiness were more likely to choose functional wines as compared with consumers with no or little trust in technology improvements ${ }^{(17)}$. This result suggests that promoting technology improvements could help to establish the market potential for low-alcohol wine.

Furthermore, it may be useful to consider the effect of labelling when investigating consumer's willingness to pay. The term 'low' might be perceived as an indication that there is something lacking or less, which could evoke negative connotations and imply that it is a product with lower quality and hence must be cheaper. Further studies should investigate the use of different terms, such as 'light wine' or 'reduced alcohol wine'. It may also be important to be aware that familiarity with labels could increase consumers' willingness to pay. Janssen and Hamm ${ }^{(29)}$ investigated consumers' willingness to pay for wines with different organic labels. They found that consumers were more willing to pay for an organic wine if the organic label was well known. They indicated higher trust in labels that they are familiar with. However, in the present study, we aimed to avoid brand influences and did therefore not provide 

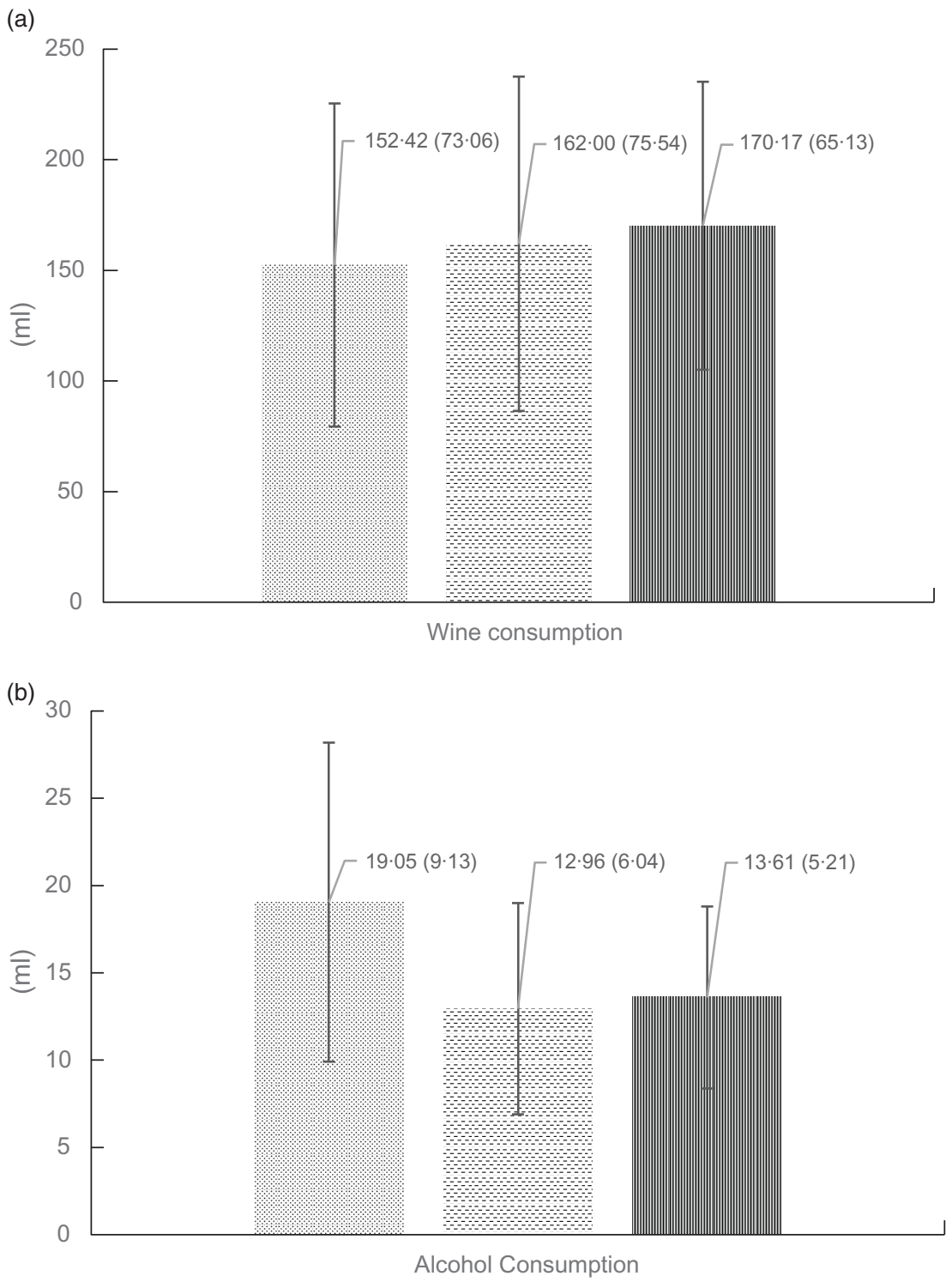

Fig. 1 Total wine and alcohol consumption Mean $M$ and standard deviation (SD) for each group. (a) The mean amount of wine consumed in the three conditions $(M=161.96, \mathrm{SD}=70.98)$ was not significantly different $\left(F_{2,86}=0.43, P=0.65\right)$. (b) The amount of alcohol consumed $(M=14.96, \mathrm{SD}=7.28)$ differed significantly $\left(F_{2,86}=6 \cdot 62, P=0.002, \eta^{2}=0.13\right)$ between the low-alcohol groups and the control group. ; Control; ; low alcohol; IIII, low alcohol blinded

the name of the wine maker to the participants. However, Tamburlaine Organic Wine is a well-known wine producer in Newcastle and it is possible that the consumers' willingness to pay would have been different, if they had been aware of the label and its wine producer. Further research on the effect of labelling should therefore be considered.

\section{Risks and benefits of low-alcohol beverages: consumption behaviour}

The third aim of the current study was to investigate how the low-alcohol wine label influences participants' consumption behaviour. A recent study by Vasiljevic etal. ${ }^{(30)}$ showed that the total amount of drink consumed increased as the indicated alcohol strength on the label decreased. In the present study, however, participants in both low-alcohol wine conditions did not drink more wine as compared with those in the standard condition and no overcompensation was found in the low-alcohol condition. The difference in experimental design may partially explain these contradicting findings: Besides presenting a wine that was 'low' in alcohol (8\%), Vasiljevic et al. ${ }^{(30)}$ also presented a wine label that suggested that the wine was 'super low' (4\%) in alcohol, and the results only showed significant differences between those offered drinks labelled as 'super low' compared with 'regular'. The findings of another recent experimental study by Masson and Aurier ${ }^{(31)}$, who performed a between-subjects comparison to measure the difference of low-alcohol (9\% alcohol) with standard 
wine consumption ( $13.5 \%$ alcohol), and a within-subjects comparison to measure the difference between a blinded and an informed condition, showed that no overcompensation was present in either of the comparisons. The present study confirms these findings and further adds to this by showing the comparison between three conditions (low-alcohol, low-alcohol blinded and control) simultaneously. The present findings are also in line with the self-reported outcomes from a study conducted by Saliba and Moran ${ }^{(32)}$ which showed that people who perceived wine as healthy reported higher frequency, but not higher volume, of consumption. Importantly, these findings resulted in a decreased alcohol intake in the present study; participants who drank low-alcohol wine consumed approximately $30 \%$ less alcohol as compared with those who drank the standard wine. When comparing the alcohol intake for the average amount of wine consumed $(162 \mathrm{ml})$, those who drank low-alcohol wine consumed approximately one standard unit, whereas those who drank the standard wine consumed 1.6 standard units. This has important practical implications; the WHO defines a standard drink as one containing $10 \mathrm{~g}$ of alcohol. Consequently, for a standard (12.5\%) wine, $100 \mathrm{ml}$ of wine equals one standard drink. However, a standard serve of wine at a restaurant or bar is $150 \mathrm{ml}$, and therefore much more than one standard drink. Interestingly, when drinking a low-alcohol wine of $8 \%$, one glass of wine (a standard serve of $150 \mathrm{ml}$ ) now equals one standard drink.

Low-alcohol beverages have been discussed to pose a risk for current abstainers, particularly for adolescents, as they might encourage them to consume an alcoholic beverage $^{(32,33)}$. Future research is needed to further investigate the effect of low-alcohol labelling on current abstainers and on individuals who are trying to limit alcohol intake or abstain from alcohol. Furthermore, future research may wish to investigate the effect of terminology and labelling on perceived strength and consumption behaviour.

\section{Strengths and limitations}

Previously, wines have been classified as de-alcoholised (<0.5\%), low-alcohol (0.5-1.2\%), reduced alcohol (1.2-6.5\%) and lower alcohol wine $(5 \cdot 5-10 \cdot 5 \%)^{(28)}$. Therefore, one could argue whether the term low-alcohol wine was correctly used in the current study. However, the classification of wines with reduced alcohol content is not explicit and varies between countries ${ }^{(7)}$. It was assumed that the term low-alcohol wine may be perceived as a more familiar term. Consequently, in the present study, the term 'low-alcohol wine' was used, to refer to a wine with $8 \%$ alcohol content and participants in the study conditions were adequately informed about the percentage of alcohol content. As some have suggested a significant difference in wine liking when the alcoholic content was reduced with $4 \%$ or less $v$. a reduction with $5.5 \%$ or more ${ }^{(12)}$, further research will need to investigate the effect of different levels of alcohol reduction on consumer's perception and consumption behaviour.
Power analysis indicates that our sample size was sufficient to detect medium to large effects. Consequently, it is possible that small effects may have remained undetected. However, there is no indication or trend that low-alcohol labelling would have led to overconsumption since the mean values for wine consumed in the low-alcohol and control (standard wine) condition were very similar. The amount of wine provided and the study duration were standardised. However, the amount of time a person has available might be an important factor influencing consumption behaviour. As time and the amount of wine were limited, one cannot exclude that consumption behaviours would have differed between the conditions in other consumption settings, for example, in a bar or at home ${ }^{(34)}$. Ceiling effects may have occurred as a consequence of the standardised amount of wine provided. Nine of the participants consumed all of the provided wine $(300 \mathrm{ml})$. However, the interpretation of results remained unchanged, if those participants were excluded from analysis. A sheet of paper was wrapped around the wine bottle in order to avoid a visual anchoring effect. However, since the participants served themselves, the weight of the bottle may still have caused an anchoring effect. Considering that the weight of the glass bottle is high relative to the weight of the wine, this effect is presumably small, however. By reporting empirical evidence on consumption behaviour, this study contributes to the existing literature, which mainly focused on self-reporting measures regarding acceptance and consumer demand for low-alcohol wine. Further research is needed to investigate whether these findings can be replicated in a larger sample and whether they can be confirmed in different settings.

\section{Conclusions}

This experimental study on low-alcohol wine perception and consumption showed that participants liked and consumed the low-alcohol wine in a similar fashion as the participants who tasted standard wine. The main reasons for the high ratings may be the recent improvements in the sensory quality and the increased health consciousness among consumers, resulting in an increase in consumer acceptance of wines with a reduced alcohol content. No overcompensation was found, resulting in an important difference in the consumed amount of pure alcohol for those who drank low-alcohol wine as compared with those who drank the standard wine. These findings suggest a potential market for low-alcohol wine. This is particularly of interest due to its important health and social benefits for consumers and the potential for the wine industry to meet consumer demand.

\section{Acknowledgements}

Acknowledgements: The authors appreciate all participants in this study for their cooperation. The authors would also 
like to acknowledge and thank the HMRI for their assistance with the recruitment through their media release. Lastly, the authors would like to acknowledge Tamburlaine Wines, NSW, Australia, who produced and provided the wine for the current study. Financial support: T.B. and K.D. are supported by the Priority Research Centre for Physical Activity and Nutrition and the Faculty of Health and Medicine, the University of Newcastle. The collaboration between the researchers was supported by the Australia-Germany Joint Research Co-operation Scheme, an initiative of Universities Australia and the German Academic Exchange Service (DAAD). No other funding was obtained for this research. Conflict of interest: None. Authorship: T.B., S.D. and E.F. conceptualised the study, developed the statistical analysis plan and conducted the analysis. E.F. drafted the initial manuscript. T.B. and E.F. coordinated and supervised data collection, and T.B., K.D., S.D. and M.W. contributed to the manuscript drafting. T.B., K.D., S.D. and M.W. edited and provided critical review of manuscript. All authors approved the final manuscript as submitted. Ethics of human subject participation: This study was conducted according to the guidelines laid down in the Declaration of Helsinki, and all procedures involving research study participants were approved by the Human Research Ethics Committee of the University of Newcastle (H-2017-0419). Written informed consent was obtained from all subjects. The study manager had a valid 'Responsible Service of Alcohol' certificate, which allows serving alcohol in Australia.

\section{Supplementary material}

For supplementary material accompanying this paper visit https://doi.org/10.1017/S1368980019005238

\section{References}

1. Chick J (2011) The WHO global strategy to reduce the harmful use of alcohol. Alcohol Alcohol 46, 223-223.

2. Griswold MG, Fullman N, Hawley C et al. (2018) Alcohol use and burden for 195 countries and territories, 1990-2016: a systematic analysis for the Global Burden of Disease Study 2016. Lancet 392, 1015-1035.

3. Lähteenmäki L (2004) Consumers and health: getting the probiotic message across. Microb Ecol Health Dis 16, 145-149.

4. Lähteenmäki L (2013) Claiming health in food products. Food Qual Prefer 27, 196-201.

5. Lockshin L \& Corsi AM (2012) Consumer behaviour for wine 2.0: a review since 2003 and future directions. Wine Econ Policy 1, 2-23.

6. Stockley C, Taylor AW, Montgomerie A et al. (2017) Changes in wine consumption are influenced most by health: results from a population survey of South Australians in 2013. Int J Wine Res 9, 13-22.

7. Saliba A, Ovington L \& Moran C (2013) Consumer demand for low-alcohol wine in an Australian sample. Int J Wine Res 5, 1-8.
8. Bucher T, Deroover K \& Stockley C (2018) Low-alcohol wine: a narrative review on consumer perception and behaviour. Beverages $\mathbf{4}, 82$.

9. Mueller S, Lockshin L \& Louviere JJ (2011) Alcohol in moderation: market potential for low alcohol wine before and after excise tax increase. In 6th Int Conf Acad Wine Bus Res. http://academyofwinebusiness.com/wp-content/uploads/ 2011/09/77-AWBR2011-Mueller_Lockshin_Louviere.pdf (accessed January 2019).

10. Bucher T, Deroover K \& Stockley C (2019) Production and marketing of low-alcohol wine. In Advances in Grape and Wine Biotechnology [A Morata \& I Loira, editors]. IntechOpen. https://www.intechopen.com/books/advancesin-grape-and-wine-biotechnology/production-and-marketingof-low-alcohol-wine (accessed June 2019).

11. Bruwer J, Jiranek V, Halstead L et al. (2014) Lower alcohol wines in the UK market: some baseline consumer behaviour metrics. Br Food J 116, 1143-1161.

12. Meillon S, Viala D, Medel M et al. (2010) Impact of partial alcohol reduction in Syrah wine on perceived complexity and temporality of sensations and link with preference. Food Qual Prefer 21, 732-740.

13. Zajonc RB (2001) Mere exposure: a gateway to the subliminal. Curr Dir Psychol Sci 10, 224-228.

14. Masson J, Aurier P \& d'hauteville F (2008) Effects of nonsensory cues on perceived quality: the case of low-alcohol wine. Int J Wine Bus Res 20, 215-229.

15. Wright CA, Bruhn CM, Heymann $\mathrm{H}$ et al. (2007) Beer and wine consumers' perceptions of the nutritional value of alcoholic and nonalcoholic beverages. J Food Sci 73, $\mathrm{H} 8-\mathrm{H} 11$.

16. Higgins LM \& Llanos E (2015) A healthy indulgence? Wine consumers and the health benefits of wine. Wine Econ Policy 4, 3-11.

17. Barreiro-Hurlé J, Colombo S \& Cantos-Villar E (2008) Is there a market for functional wines? Consumer preferences and willingness to pay for resveratrol-enriched red wine. Food Qual Prefer 19, 360-371.

18. Soleas GJ, Grass L, Josephy PD et al. (2002) A comparison of the anticarcinogenic properties of four red wine polyphenols. Clin Biochem 35, 119-124.

19. Rehm J, Lachenmeier DW, Llopis EJ et al. (2016) Evidence of reducing ethanol content in beverages to reduce harmful use of alcohol. Lancet Gastroenterol Hepatol 1, $78-83$.

20. Higgs S, Stafford LD, Attwood AS et al. (2008) Cues that signal the alcohol content of a beverage and their effectiveness at altering drinking rates in young social drinkers. Alcohol Alcohol 43, 630-635.

21. Provencher V, Polivy J \& Herman CP (2009) Perceived healthiness of food. If it's healthy, you can eat more! Appetite 52, 340-344.

22. Wansink B \& Chandon P (2006) Can 'low-fat' nutrition labels lead to obesity? J Mark Res 43, 605-617.

23. Faul F, Erdfelder E, Lang A-G et al. (2007) G*Power 3: a flexible statistical power analysis program for the social, behavioral, and biomedical sciences. Behav Res Methods 39, 175-191.

24. Bui K, Dick R, Moulin G et al. (1986) A reverse osmosis for the production of low ethanol content wine. Am J Enol Vitic 37, 297-300.

25. Catarino M, Mendes A, Madeira L et al. (2006) Beer dealcoholization by reverse osmosis. Desalination 200, 397-399.

26. d'Hauteville F (1994) Consumer acceptance of low alcohol wines. Int J Wine Mark 6, 35-48.

27. Chrysochou P (2014) Drink to get drunk or stay healthy? Exploring consumers' perceptions, motives and preferences for light beer. Food Qual Prefer 31, 156-163. 
28. Pickering GJ (2000) Low- and reduced-alcohol wine: a review. $J$ Wine Res 11, 129-144.

29. Janssen M \& Hamm U (2012) Product labelling in the market for organic food: consumer preferences and willingnessto-pay for different organic certification logos. Food Qual Prefer 25, 9-22.

30. Vasiljevic M, Couturier D-L, Frings D et al. (2018) Impact of lower strength alcohol labeling on consumption: a randomized controlled trial. Health Psychol 37, 658-667.

31. Masson J \& Aurier P. (2017) Modifying wine alcohol content: sensory and non-sensory impacts on quantities consumed. Int J Entrep Small Bus 32, 102.
32. Saliba AJ \& Moran CC (2010) The influence of perceived healthiness on wine consumption patterns. Food Qual Prefer 21, 692-696.

33. Sornpaisarn B, Shield KD, Cohen JE et al. (2015) Can pricing deter adolescents and young adults from starting to drink: an analysis of the effect of alcohol taxation on drinking initiation among Thai adolescents and young adults. J Epidemiol Glob Health 5, 45-57.

34. Meillon S, Urbano C, Guillot G et al. (2010) Acceptability of partially dealcoholized wines - measuring the impact of sensory and information cues on overall liking in real-life settings. Food Qual Prefer 21, 763-773. 